\title{
Primary Sjögren Syndrome: A review for health professionals
}

\author{
Ricardo Hsieh ${ }^{1,2 *}$ and Silvia Vanessa Lourenço ${ }^{1,2}$ \\ ${ }^{1}$ Institute of Tropical Medicine, University of São Paulo, Brazil \\ ${ }^{2}$ Department of Stomatology, School of Dentistry, University of São Paulo, Brazil
}

\begin{abstract}
Primary Sjögren Syndrome (PSS), also known as autoimmune epithelitis, it is an autoimmune disease with a large clinical features spectrum, from local exocrinopathy to multiple systemic manifestations. The main symptoms are xerostomia and xerophthalmia, often accompanied by systemic changes those affects parenchymal organs.

The frequently associated clinical signs of PSS in the oral cavity are: loss of brightness, dryness, pale and thin appearance of oral mucosa, fissures and lobulations in the lingual dorsum, angular cheilitis and filiform papillae atrophy. And the clinical symptoms are: glossodynia (mouth burning), dysgeusia (distortion or decreased taste), speech and swallowing the bolus difficulties, dry cough, difficulty in fixing dental prostheses.

It is known that genetic, hormonal and environmental factors seem to be related to the development PSS, which is associated with increasedHLA-B8 / DR3 halotype frequency. The inflammatory target in the disease is primarily the epithelium of the lacrimal and salivary glands and, therefore, some authors named the destruction of the glandular parenchyma in PSS, whose initial mechanisms may be related to the breakdown of homeostasis in glandular architecture (cell-cell and cell- extracellular matrix structures) as autoimmune epithelitis.

One of the main characteristics of this disease is the destruction of the salivary glands parenchyma, consequently decreasing salivary flow and xerostomia. The dentist plays an important role within the multidisciplinary team, with meticulous instructions on oral hygiene, non-cariogenic diet advice, prescription lubricating agents and constant evaluation of dental restorations to give the patients a better health well- being.
\end{abstract}

\section{Introduction}

The clinical features of Sjögren Syndrome were earliest described by Henrik Sjögren in 1933 as an extremely dryness of the oral mucosa and eyes in female patients, in addition to probable rheumatoid arthritis [1].

Primary Sjögren Syndrome (PSS), also known as autoimmune epithelitis, it is an autoimmune disease with a large clinical features spectrum, from local exocrinopathy (involving salivary and lacrimal glands) to multiple systemic manifestations [2,3]. Initially, the main symptoms are xerostomia and xerophthalmia, often accompanied by systemic changes that affects parenchymal organs, such as lungs, kidneys and liver, in addition to the association with lymphoproliferative agents which could culminate in lymphoma development [4,5].

\section{PSS classification}

In 2002, it was published the first international consensus on the classification criteria for PSS according to the proposition of The American-European Consensus Group (AECG) [6]. Later, in 2012, the American College of Rheumathology (ACR) added new criteria into PSS classification suggested Sjögren's International Collaborative Clinical Alliance (SICCA), which focused three main alterations: keratoconjunctivitis sicca; sialoadenitis; serological factors [7].

In 2017, ACR and European League Against Rheumatism (EULAR) published the newest methodological consensus, which supported PSS early diagnosis, thus patients showing PSS symptoms could be diagnosed precociously based on objective criteria as: positive serological exam; focal lymphocytic sialadenitis (focal score $\geq 1$ foci
/ $4 \mathrm{~mm}^{2}$ ); oral and ocular objective criteria described at Table 1 . Interestingly, this last classification has been showing higher sensibility (96\%) and specificity (95\%) compared to previous classifications, therefore it has been considered a valuable method for PSS diagnosis. And this method does not exempt clinical experience of the health professional facing all different cases [8].

\section{Clinical and epidemiological features}

The prevalence of Primary Sjögren Syndrome in general population is about $0.1 \%$ to $0.5 \%[9,10]$. PSS can affect any age, however there is a greater incidence in individuals between the 4 th and 5 th decades of life. Notably, women more affected than men (9:1) [11-14].

Clinically, mucosal dryness is the most common characteristic found among PSS patients, mainly oral and ocular mucosa. Often, patients may have difficulty to accurately determine the onset of the disease, thus symptoms can be easily ignored or misunderstood [15].

In this syndrome, the dry eye symptom can be present even the eyes appearance do not show any changes. Xerophthalmia is defined

*Correspondence to: Ricardo Hsieh, DDS, PhD, Avenida Doutor Enéas de Carvalho Aguiar, NO. 500, Prédio II, 2o Andar, São Paulo, SP, Brazil - CEP: 05403-000, Tel: +551130617064/+5511966369564; E-mail: r.hsieh@usp.br

Key words: sjögren syndrome, dentist, oral mucosa, ocular mucosa

Received: August 03, 2020; Accepted: August 24, 2020 Published: August 27, 2020 
Table 1. The PSS classification applies to any individual who meets inclusion criteria*, who has none of the conditions listed as exclusion criteria**, and total score $\geq 4$ when the individual score of each of the five items below are added

\begin{tabular}{|l|c|}
\hline Item & Score \\
\hline $\begin{array}{l}\text { Lip salivary gland with focal lymphocytic sialadenitis and focal score } \geq 1 \text { foci } \\
/ 4 \mathrm{~mm}^{2}\end{array}$ & 3 \\
\hline Positive Anti-SSA / Ro & 3 \\
\hline Ocular color score $\geq 5$ (or score of van Bijsterveld $\geq 4$ ), at least in one eye & 1 \\
\hline Schirmer test $\leq 5 \mathrm{~mm} / 5 \mathrm{~min}$, at least in one eye & 1 \\
\hline Unstimulated total salivary flow rate $\leq 0.1 \mathrm{ml} / \mathrm{min}$ & 1 \\
\hline
\end{tabular}

* Inclusion criteria: (1) Daily and persistently dry eyes sensation > 3 months; (2) recurrent feeling of sand in the eyes; (3) Artificial tear use > three times daily; (4) Daily feeling of dry mouth for $>$ three months; (5) often drink fluids to help swallow dry food.

** Exclusion criteria: (1) Head \& Neck Radiation therapy history; (2) active C hepatitis infection (confirmed by reaction polymerase chain - PCR; (3) AIDS; (4) Sarcoidosis; (5) Amiloidosis; (6) GVHD; IgG4 related disease.

by decreased tear production, and it is capable to cause the destruction of the conjunctiva and cornea, and this clinical condition is called sicca keratoconjunctivitis. The most common symptoms are: burning, feeling foreign body in the eyes, itching, redness and photosensitivity [16]. There are several inflammatory effects that could culminate in vision loss, such as: scleritis, inflammatory nodules on the surface and corneal ulcer [15].

PSS is commonly associated to hyposalivation (decreased production of salivary flow and the amount of produced saliva is $\leq$ to $0.1 \mathrm{~mL} / \mathrm{min}$ ) and xerostomia (subjective feeling dry mouth) $[17,18]$.

In PSS, the reduced flow salivary can be considered as a biomarker hypofunction of the salivary glands [19-21], facilitating the accumulation of dental plaque and the emergence of dental cavities, periodontal diseases and opportunistic infections [16,20,22]. In this disease, the decrease and/or loss of salivary secretion is caused by the destruction of the glandular parenchyma, mainly due to a chronic inflammation that destroys structure of the salivary glands [19].

The frequently associated clinical signs of PSS in the oral cavity are: loss of brightness, dryness, pale and thin appearance of oral mucosa, fissures and lobulations in the lingual dorsum, angular cheilitis and filiform papillae atrophy. And the clinical symptoms are: glossodynia (mouth burning), dysgeusia (distortion or decreased taste), speech and swallowing the food difficulties, dry cough, difficulty in fixing dental prostheses. Another symptom that can manifest is edema of the major salivary glands, most commonly parotid glands, it is essential to verify the existence of ascending bacterial infection or even lymphoma development [16].

The differential diagnosis of PSS should be performed with other possible diseases, which also cause xerostomia, such as: previous Head \& Neck Radiation therapy; C hepatitis infection; AIDS; Lymphoma; Sarcoidosis; Amiloidosis; hemochromatosis and GVHD [20].

Moreover, there are several systemic manifestations which PSS patients could show due to the disease complexity: vasculitis; arthralgia and arthritis; fribromyalgia; myopathy; esophageal hypomobility; atrophic gastritis; xerotracheal; lung interstitial disease; bronchiolitis; pericarditis; cranial neuropathy; peripheral polyneuropathy; increased risk of congenital atrioventricular block in babies whose mothers have positivity for anti-SSA /Ro and anti-SSB-La [2,23]. Additionally, 5\% to $10 \%$ of PSS patients can develop non-Hodgkin's lymphoma, which is approximately 20 times greater risk than general population [15].

\section{Etiopathogenesis}

It is known that genetic, hormonal and environmental factors seem to be related to the development PSS, which is associated with increased HLA-B8 / DR3 halotype frequency [1,3,24]. Dysfunctions of hormones may be part of the pathophysiology development of PSS, mainly deficiencies of androgens, estrogen and progesterone $[25,26]$.

Environmental factors and, particularly, viral infections act as a potential trigger for the PSS development, such as: Epstein-Barr (EBV), HTLV-1 (human T leukemia vírus-1), Coxsackievirus, C-hepatitis Virus (CHV) [20,24]. Meantime, the most important etiological agent is EBV, which transmission occurs by intimate contact with the infected host's saliva, resulting in an acute infectious mononucleosis $[27,28]$.

During primary infection, EBV replication occurs in the oropharynx, specifically inside pharyngeal epithelial cells, epithelial cells of salivary glands and B lymphocytes. As a result, the virus is not eliminated from the organism, persisting in its latent form in immunocompetent adult patients, or can be later reactivated [29].

The genetic material of the EBV can be extracted from PSS patient minor salivary glands tissue biopsy, which has been studied by many researches, and it is believed that it plays a role in the pathogenesis of PSS, acting as a triggering factor of the disease in genetically predisposed individuals [27]. Indeed, the mechanism of molecular mimicry occurs between EBV proteins and host antigens, particularly with the SSA (Ro) antigen, which can lead to a humoral immune response directed against autoantigens, characterizing the autoimmune disease [30].

In this multifactorial scenario, the disease mechanism model in PSS incorporates genetic, histopathological and serological changes, with local and systemic repercussions, including the following steps:

o Initial aggression to the glandular epithelium (epithelitis with architectural changes) [3];

o Apoptosis and presentation of autoantigens anti-SSA (Ro) and antiSSB (La) on the glandular surface [31];

o Alteration of the intraglandular endothelium, proteins, adhesion molecules and cytokines production by the damaged gland [3];

o Infiltration and activation of lymphocytes mediated by antigen presenting cells [32];

o Production of interferon gamma (IFN- $\gamma$ ) by presenting antigens cells, which perpetuates the inflammatory response and the secretion of metalloproteinases, which will alter the glandular parenchyma (apoptosis) and the stroma [33].

This complex mechanism then becomes in a vicious cycle until the complete destruction of the glandular parenchyma and subsequent fibrosis, reflecting on the quality and quantity of produced saliva. Morpho-architectural changes result in changes in the aquaporin channels, which significantly alters the saliva production, leading to xerostomia even before complete destruction of the affected salivary glands [33].

\section{Histopathological features}

It is known that mammals have the salivary gland (structurally is composed of acini and a duct system), which play an important role in the production and modification of saliva, and conduction of salivary secretion into the oral cavity [34]. Anatomically there are three pairs of major salivary glands (parotid, submandibular and sublingual), in 
addition, there are numerous minor salivary glands distributed in the oral mucosa.

The inflammatory target in the disease is primarily the epithelium of the lacrimal and salivary glands and, therefore, some authors named the destruction of the glandular parenchyma in PSS, whose initial mechanisms may be related to the breakdown of homeostasis in glandular architecture (cell-cell and cell- extracellular matrix structures) as autoimmune epithelitis [3].

There is a consensus about PSS diagnosis and monitoring the progression of the disease by lip salivary glands biopsies analysis, because its morbidity is very low comparing to the biopsy of major salivary glands [8]. In addition, these glands are easily accessible, are located on a muscle layer and separated from the oral mucosa by a thin connective tissue. The surgery procedure is performed using local anesthesia in an outpatient setting by professionals with stomatology knowledge.

According to ACR, the classic histopathological feature for PSS diagnosis is the presence of focal lymphocytic sialadenitis, characterized by at least an inflammatory focus, which is composed of an aggregate of 50 or more lymphocytes in $4 \mathrm{~mm}^{2}$ glandular tissue, at least in 4 lobes of labial mucous salivary glands [6].

In this context, inflammation presents itself as the central point in the destruction of the glandular parenchyma, unlikely salivary glands from individuals without any autoimmune disease. In the affected glands it is possible observe the destruction of the acini, extensive fibrosis and periductal lymphocytosis, through histopathological analysis of minor salivary glands by professionals with knowledge in oral pathology.

\section{Treatment}

The early diagnosis and treatment of PSS are vital to prevent complications in the oral cavity. The complexity of the syndrome indicates that best way to treat this disease is through a multidisciplinary approach, including: dentist, ophthalmologist and rheumatologist $[36,37]$.

The medical team is responsible for preparing diagnosis and control systemically symptomatology, for example, prescription of immunosuppressants and lubricating eye drops, thus providing an improvement in the quality of life of patients with PSS [20]. Concerning oral cavity, clinical manifestations are due decrease in salivary secretion and, therefore, treatment should aim to minimize the damage caused by xerostomia, which becomes a challenge in dental treatment, as the lack of saliva, consenquently, reduces the durability of restorations, increasing marginal infiltrations in resins and promoting the increase of carious lesions $[16,38,39]$. In fact, there is a change in the oral microbiota contributing to a biofilm with a more cariogenic and acidophilic profile, thus raising the risk for cavities and candidiasis [39].

In this scenario, glandular dysfunctions can directly affect selfesteem, social interactions and well-being sensation of affected patients [40]. Thus, it is essential that patients carry out periodic and rigorous monitoring with a dentist, performing good hygiene, using dental floss, brush regularly with fluoride dentifrice, be oriented regarding the noncariogenic diet pattern, besides control of periodontal disease, dental caries and treatment of opportunistic infections, such as candidiasis, which can be resolved from the antifungal prescription [16,20,39].

PSS patients should avoid diuretic, antihypertensive drugs, antidepressants and antihistamines, as they can worsen salivary hypofunction [40]. The prescription of artificial saliva, lubricating gels or mouthwash can be beneficial for patients with severe oral dryness, however, some may present some resistance regarding the use artificial saliva due to the short duration of moistening effect and unpleasant taste. Finally, it is recommended to the patients regularly to intake small sips of water, and avoiding caffeine, tabacco, alcoholic drinks.

\section{Conclusion}

One of the main characteristics of this disease is the destruction of the salivary glands parenchyma, consequently decreasing salivary flow and xerostomia. The dentist plays an important role within the multidisciplinary team, with meticulous instructions on oral hygiene, non-cariogenic diet advice, prescription of lubricating agents and constant evaluation of dental restorations to give the patients a support of better health well-being.

\section{Conflicts of interest}

The authors declare there is no conflicts of interest.

\section{References}

1. Fox RI (2005) Sjogren's syndrome. The Lancet 366(9482): 321-331.

2. Al-Hashimi I, Khuder S, Haghighat N, Zipp M (2001) Frequency and predictive value of the clinical manifestations in Sjögren's syndrome. J Oral Pathol Med 30(1): 1-6. [Crossref]

3. Mavragani CP, Moutsopoulos HM (2014) Sjögren's syndrome. Annu Rev Pathol 9: 273-285.

4. Skopouli FN, Dafni U, Ioannidis JP, Moutsopoulos HM (2000) Clinical evolution, and morbidity and mortality of primary Sjögren's syndrome. Semin Arthritis Rheum 29(5): 296-304

5. Tzioufas AG, Voulgarelis M (2007) Update on Sjögren's syndrome autoimmune epithelitis: from classification to increased neoplasias. Best Pract Res Clin Rheumatol 21(6): 989-1010.

6. Vitali C, Bombardieri S, Jonsson R, Moutsopoulos HM, Alexander EL, et al. (2002) Classification criteria for Sjögren's syndrome: a revised version of the European criteria proposed by the American-European Consensus Group. Ann Rheum Dis 61(6): 554-558. [Crossref]

7. Shiboski SC, Shiboski CH, Criswell L, Baer A, Challacombe S, et al. (2012) American College of Rheumatology classification criteria for Sjögren's syndrome: a data-driven, expert consensus approach in the Sjögren's International Collaborative Clinical Alliance cohort. Arthritis Care Res (Hoboken) 64(4):475-487. [Crossref]

8. Shiboski CH, Shiboski SC, Seror R, Criswell LA, Labetoulle M, et al. (2016) American College of Rheumatology/European League against rheumatism classification criteria for primary Sjögren's syndrome: a consensus and data-driven methodology involving three international patient cohorts. Arthritis Rheumatol 69(1): 35-45.

9. Bowman SJ, Ibrahim GH, Holmes G, Hamburger J, Ainsworth JR (2004) Estimating the prevalence among Caucasian women of primary Sjögren's syndrome in two general practices in Birmingham, UK. Scand J Rheumatol 33(1): 39-43.

10. Sánchez-Guerrero J, Pérez-Dosal MR, Cárdenas-Velázquez F, Pérez-Reguera A, CelisAguilar E, et al. (2005) Prevalence of Sjögren's syndrome in ambulatory patients according to the American-European Consensus Group criteria. Rheumatology (Oxford) 44(2): 235-240.

11. Bell M, Askari A, Bookman A, Frydrych S, Lamont J, et al. (1999) Sjögren's syndrome: A critical review of clinical management. J Rheumatol 26(9): 2051-2061. [Crossref]

12. Bowman SJ, Pillemer S, Jonsson R, Asmussen K, Vitali C, et al. (2001) Revisiting Sjögren's syndrome in the new millennium: perspectives on assessment and outcome measures: report of a workshop held on 23 March 2000 at Oxford, UK. Rheumatology (Oxford) 40(10): 1180-1188.

13. García-Carrasco M, Ramos-Casals M, Rosas J, Pallarés L, Calvo-Alen J, et al. (2002) Primary Sjögren syndrome: clinical and immunologic disease patterns in a cohort of 400 patients. Medicine (Baltimore) 81(4): 270-280. [Crossref]

14. Rozman B, Novljan MP, Hocevar A, Ambrozic A, Zigon P, et al. (2004) Epidemiology and diagnostics of primary Sjögren's syndrome. Reumatizam 51(2): 9-12. 
15. Sutcliffe N (2006) Sjögren's syndrome. Medicine (Abingdon) 34(11): 476-79.

16. Kassan SS, Moutsopoulos HM (2004) Clinical manifestations and early diagnosis of Sjögren syndrome. Arch Intern Med 164(12): 1275-1284.

17. Sreebny LM, Schwartz SS (1997) A reference guide to drugs and dry mouth: 2nd edition. Gerodontology 14(1): 33-47.

18. Plemons JM, Al-Hashimi I, Marek CL, American Dental Association Council on Scientific Affairs (2014) Managing xerostomia and salivary gland hypofunction: executive summary of a report from the American Dental Association Council on Scientific Affairs. J Am Dent Assoc 145(8): 867-873. [Crossref]

19. Proctor GB (2016) The physiology of salivary secretion. Periodontol 2000 70(1): 1125. [Crossref]

20. Bowman SJ (2010) Sjögren syndrome. Medicine (Abingdon) 38(2):105-8.

21. Turner MD (2016) Hyposalivation and Xerostomia: Etiology, Complications, and Medical Management. Dent Clin North Am 60(2): 435-443. [Crossref]

22. Mavragani CP, Moutsopoulos HM (2010) The geoepidemiology of Sjögren's syndrome. Autoimmun Rev 9(5): A305-10. [Crossref]

23. Vissink A, Bootsma H, Kroese FG, Kallenberg CG (2012) How to assess treatment efficacy in Sjögren's syndrome? Curr Opin Rheumatol 24(3): 281-289.

24. Ramos-Casals M, Tzioufas AG, Stone JH, Siso A, Bosch X (2010) Treatment of primary Sjögren syndrome: a systematic review. JAMA 304(4): 452-460. [Crossref]

25. Hansen A, Lipsky PE, Dörner T (2003) New concepts in the pathogenesis of Sjögren syndrome: Many questions, fewer answers. Curr Opin Rheumatol 15(5): 563-570.

26. Hayashi Y, Arakaki R, Ishimaru N (2004) Apoptosis and estrogen deficiency in primary Sjögren syndrome. Curr Opin Rheumatol 16(5): 522-526. [Crossref]

27. Delaleu N, Jonsson MV, Appel S, Jonsson R (2008) New concepts in the pathogenesis of Sjögren's syndrome. Rheum Dis Clin North Am 34(4): 833-845. [Crossref]

28. Hislop AD (2015) Early virological and immunological events in Epstein-Barr virus infection. Curr Opin Virol 15: 75-79. [Crossref]
29. Mariette X, Gozlan J, Clerc D, Bisson M, Morinet F (1991) Detection of Epstein-Barr virus DNA by in situ hybridization and polymerase chain reaction in salivary gland biopsy specimens from patients with Sjögren's syndrome. Am J Med 90(3): 286-294. .

30. Pasoto SG, Natalino RR, Chakkour HP, Viana VST, Bueno C, et al. (2013) EBV reactivation serological profile in primary Sjögren's syndrome: an underlying trigger of active articular involvement? Rheumatol Int 33(5): 1149-1157. [Crossref]

31. Yannopoulos DI, Roncin S, Lamour A, Pennec YL, Moutsopoulos HM, Youinou P (1992) Conjunctival epithelial cells from patients with Sjögren's syndrome inappropriately express major histocompatibility complex molecules, La(SSB) antigen, and heat-shock proteins. J Clin Immunol 12(4): 259-265. [Crossref]

32. Routsias JG, Tzioufas AG (2007) Sjögren's syndrome: study of autoantigens and autoantibodies. Clin Rev Allergy Immunol 32(3): 238-251.

33. Barrera MJ, Bahamondes V, Sepúlveda D, Quest AF, Castro I, et al. (2013) Sjögren's syndrome and the epithelial target: a comprehensive review. J Autoimmun 42: 7-18.

34. Tandler B (1993) Introduction to mammalian salivary glands. Microsc Res Tech 26(1) 1-4. [Crossref]

35. Delli K, Vissink A, Spijkervet FKL (2014) Salivary gland biopsy for Sjögren's syndrome. Oral Maxillofac Surg Clin North Am 26(1): 23-33.

36. Valim V, Trevisani VFM, Pasoto SG, Serrano EV, Ribeiro SLE, et al. (2015) Recommendations for the treatment of Sjögren's syndrome. Rev Bras Reumatol 55(5): 446-457.

37. Both T, Dalm VASH, van Hagen PM, van Daele PLA (2017) Reviewing primary Sjögren's syndrome: beyond the dryness: From pathophysiology to diagnosis and treatment. Int J Med Sci 14(3): 191-200. [Crossref]

38. Stefanski AL, Tomiak C, Pleyer U, Dietrich T, Burmester GR, Dorner T (2017) The Diagnosis and Treatment of Sjögren's syndrome. Dtsch Arztebl Int 114(20): 354-361. [Crossref]

39. González S, Sung H, Sepúlveda D, González M, Molina C (2014) Oral manifestation and their treatment in Sjögren's syndrome. Oral Dis 20(2): 153-161. [Crossref]

40. Soto-Rojas AE, Kraus A (2002) The oral side of Sjögren syndrome: diagnosis and treatment: a review. Arch Med Res 33(2): 95-106. [Crossref]

Copyright: (C2020 Hsieh R. This is an open-access article distributed under the terms of the Creative Commons Attribution License, which permits unrestricted use, distribution, and reproduction in any medium, provided the original author and source are credited. 